\title{
Species by Environment Interactions Affect Pyrrolizidine Alkaloid Expression in Senecio jacobaea, Senecio aquaticus, and Their Hybrids
}

\author{
Heather Kirk • Klaas Vrieling • \\ Eddy Van Der Meijden • Peter G. L. Klinkhamer
}

Received: 17 December 2009/Revised: 9 February 2010 /Accepted: 5 March 2010 /Published online: 23 March 2010

(C) The Author(s) 2010. This article is published with open access at Springerlink.com

\begin{abstract}
We examined the effects of water and nutrient availability on the expression of the defense pyrrolizidine alkaloids (PAs) in Senecio jacobaea and S. aquaticus. Senecio jacobaea, and S. aquaticus are adapted to different natural habitats, characterized by differing abiotic conditions and different selection pressures from natural enemies. We tested if PA concentration and diversity are plastic over a range of water and nutrient treatments, and also whether such plasticity is dependent on plant species. We also tested the hypothesis that hybridization may contribute to PA diversity within plants, by comparing PA expression in parental species to that in artificially generated $F_{1}$ hybrids, and also in later generation natural hybrids between $S$. jacobaea and S. aquaticus. We showed that total PA concentration in roots and shoots is not dependent on species, but that species determines the pattern of PA diversification. Pyrrolizidine alkaloid diversity and concentration are both dependent on environmental factors. Hybrids produce a putatively novel PA, and this PA is conserved in natural hybrids, that are backcrossed to $S$. jacobaea. Natural hybrids that are backcrossed several times to $S$. jacobaea are with regard to PA diversity significantly different from $S$. jacobaea but not from $S$. aquaticus, while $\mathrm{F}_{1}$ hybrids are in all cases more similar to $S$. jacobaea. These results collectively suggest that PA diversity is under the influence of natural selection.
\end{abstract}

H. Kirk $(\bowtie) \cdot K$. Vrieling $\cdot$ E. Van Der Meijden $\cdot$

P. G. L. Klinkhamer

Plant Ecology Section, Institute of Biology, Leiden University, P.O. Box 9505, 2300 RA Leiden, The Netherlands

e-mail: hkirk10@hotmail.com
Key Words Hybridization · Secondary metabolite diversity · Plant resistance - Alkaloid composition . Phenotypic plasticity

\section{Introduction}

Plants mediate interactions with herbivores and pathogens by production and distribution of secondary metabolites among various plant tissues. Herbivores are either deterred by (van Dam et al. 1995; Macel et al. 2005) or attracted to (Rauscher 2001) secondary metabolites. The community of soil organisms in the plant rhizosphere also is often determined by the composition of secondary metabolites in plant roots (Hol et al. 2004; Kowalchuk et al. 2006), and such metabolites can decrease growth of particular microbial species, and stimulate the growth of others ( $\mathrm{Hol}$ and van Veen 2002). A single plant species often possesses many structural variations within single classes of secondary metabolites, and often it has been hypothesized that diversity of secondary metabolites is partially explained by selection pressure by herbivores and pathogens (Hol and van Veen 2002; Adler and Kittelson 2004; Macel et al. 2005; Albrechtsen et al. 2007). In many cases, environmental factors also are correlated with large variations in concentration, allocation, and diversity of secondary metabolites (Holton et al. 2003; Close et al. 2005; Loney et al. 2006).

Pyrrolizidine alkaloids (PAs) occur in a number of families including Apocynaceae, Asteraceae, Boraginaceae, and Orchidaceae (Hartmann and Witte 1995). They are toxic to generalist mammalian (Cheeke 1988) and insect (van Dam et al. 1995; Macel et al. 2005) herbivores, and may play a role in pathogen resistance (Hol and van Veen 2002; Kowalchuk et al. 2006). Pyrrolizidine alkaloid 
composition, including concentration and diversity, exhibits some plasticity, and can alter in response to plant developmental cues (Schaffner et al. 2003), abiotic environment (Macel and Klinkhamer 2009), and interactions with natural enemies (Hol et al. 2004).

The Senecio genus (Asteraceae) contains more than 1500 species and, the production of PAs is widespread. In Senecio, PAs are synthesized as senecionine $N$-oxide in plant roots (Hartmann and Toppel 1987). Senecionine $\mathrm{N}$-oxide is transported through the phloem to the shoots (Hartmann and Dierich 1998) where diversification into a number of related PA structures occurs. PA diversification is species specific, such that the suite of PAs within a plant species is generally unique (e.g., Pelser et al. 2005). Furthermore, significant variation in PA composition and concentration within Senecio species has been observed (Trigo et al. 2003; Macel et al. 2004).

We investigated the effects of both the abiotic environment, and of plant hybridization on the concentration and diversity of PAs expressed in the roots and shoots of Senecio aquaticus and Senecio jacobaea. The habitats of $S$. jacobaea and $S$. aquaticus are largely differentiated based on the organic and water content of the soil (Kirk et al. 2005b). Additionally, selection pressure by herbivores differs between the two species, partially because the wet soils found around natural $S$. aquaticus populations do not support the lifecycles of many invertebrate herbivores (see below).

We expect that differences in PA expression among species are due to different selection pressures over time. Because the environments of S. jacobaea and S. aquaticus are different, we also expect that these species may differentially alter production, allocation, and diversification of PAs according to environmental cues (e.g., Hol et al. 2003). For example, seasonal inundation excludes some root-associated herbivores from the habitat of $S$. aquaticus, and we thus expect that PAs associated with those herbivores are regulated differently in the roots of $S$. aquaticus from in S. jacobaea. Several studies have shown that environmental factors have an impact on PA expression in S. jacobaea (Macel 2003; Hol et al. 2003; Macel and Klinkhamer 2009).

Furthermore, $S$. jacobaea hybridizes in nature with $S$. aquaticus (Kirk et al. 2004). Natural hybrids between $S$. jacobaea and S. aquaticus, first observed at the Zwanenwater nature reserve in The Netherlands in 1979 (Ruud van der Meijden, personal communication), can be found in a narrow zone spanning a bank at the edge of a lake, which is intermediate to parental sites with regards to soil organic content and humidity (Kirk et al. 2005b). A previous study showed that natural hybrids are similar to $S$. jacobaea with regard to growth characteristics when subject to drought and flood-like conditions, while $F_{1}$ hybrids possess the drought resistant characteristics of $S$. jacobaea, and the flood resistant characteristics of $S$. aquaticus (Kirk et al. 2005b).

It has been postulated that hybridization may provide a mechanism for rapid evolution of resistance to parasites, including herbivores and pathogens. Hybridization creates a greater range of phenotypic variation than is found in parental species (Rieseberg et al. 1999; Kirk et al. 2005a; Wissemann 2007). If resistance traits exhibit higher variation among hybrid individuals than among parental species, hybrids may be more responsive to selection pressure than pure parental species. This hypothesis has been supported empirically (though not in relation to parasite resistance) in Drosophila, for which several studies have shown that variation in abiotic stress resistance can be higher in hybrid lines than in parental lines (Hercus and Hoffman 1999), such that hybrids may evolve more quickly in response to stress than parental species. Additionally, epistatic interactions among genes combined from both parents may create unique resistance traits, such as novel secondary metabolites (Fritz 1999; Orians 2000), and hybrid lines or hybrid genes may be selectively favoured.

Here, we investigated the effects of species by environment interactions on quantitative and qualitative expression of PAs in S. jacobaea, S. aquaticus, and their hybrids. We asked: i) Are there quantitative and qualitative differences in the expression of PAs between S. jacobaea, S. aquaticus, and their hybrids? ii) Do environmental factors affect PA expression in S. jacobaea, S. aquaticus, and their hybrids? iii) Is there evidence that novel PAs are produced in hybrids?

\section{Methods and Materials}

Study System Viable hybrids between S. jacobaea L. and S. aquaticus Hill have been reported from a number of locations including the United Kingdom (Stace 1975), Germany (Christian Düring, personal communication), and The Netherlands (Kirk et al. 2004). In this investigation, we studied S. jacobaea, S. aquaticus, and natural hybrids individuals sampled from the Zwanenwater reserve, located immediately to the South of Callantsoog, The Netherlands $\left(52^{\circ} 50^{\prime} 00^{\prime} \mathrm{N}, 004^{\circ} 41^{\prime} 00^{\prime \prime} \mathrm{E}\right)$. Composed mostly of sand dunes, the Zwanenwater reserve contains a small lake around which a hybrid population exists (see Kirk et al. 2005b for diagram). Senecio jacobaea is abundant in the dunes surrounding the lake, while $S$. aquaticus occurs infrequently at the lake fringe.

Selection pressure by specialist herbivores on $S$. jacobaea may be quite high, since a number of specialist herbivores, including Tyria jacobaeae and Longitarsus jacobaeae, cause extreme damage to above ground and 
below ground plant parts. Senecio aquaticus is not subject to attack by $T$. jacobaeae, and other specialists that pupate in the soil around the plant, because pupae do not survive in the moist environments where $S$. aquaticus is found (personal observation). Thrips appear to be common in the $S$. aquaticus population (personal observation). Preliminary tests showed that in climate chamber experiments, $S$. aquaticus and $S$. jacobaea were equally susceptible to $T$. jacobaeae (Macel et al. 2002), and the generalist lepidopteran herbivore Spodoptera exigua (personal observation), but $S$. aquaticus was more resistant to the generalist thrips species Thrips tabaci than S. jacobaea (Kirk et al. 2005a).

Senecio aquaticus usually is found in seasonally waterlogged, humic, chalk-poor, and nutrient-rich soils (Weeda and Van Deursen 1994), while S. jacobaea prefers sunny environments with sparse vegetation (Weeda and Van Deursen 1994). Senecio jacobaea is able to elongate its roots rapidly in response to drought, in order to reach water sources that are unavailable to $S$. aquaticus, and $S$. aquaticus is resistant to flooding, while $S$. jacobaea is not (Kirk et al. 2005b).

Seeds of S. jacobaea, S. aquaticus, and natural hybrids were collected from plants in the field during 2001 and 2002. Putative hybrids were identified based on leaf lobe and flower morphology, and were later confirmed to be hybrids based on diagnostic amplified fragment length polymorphism (AFLP) markers (Kirk et al. 2004).

$\mathrm{F}_{1}$ hybrids were produced by collecting from the field second year rosettes of parental plants that exhibited the development of flowering stems. Second year rosettes were collected because parental plants generally do not flower until their second year of growth, after vernalization (Kirk et al. 2005c). To minimize chances that introgressive genes were present in experimental parents, S. aquaticus individuals were collected from a marshy agricultural grassland approximately $500 \mathrm{~m}$ from the hybrid zone, and $S$. jacobaea individuals were collected from dunes located approximately $300 \mathrm{~m}$ from the hybrid zone. Plants from both species were placed in a greenhouse, allowed to flower, and were crossed in pairs of $S$. jacobaea $\times S$. aquaticus by rubbing flower heads together. Both species are self-incompatible (Kirk et al. 2005c). Seeds were harvested from both parental plants to be certain that maternal effects are not involved in patterns of PA expression in $\mathrm{F}_{1}$ hybrid offspring.

Effects of Environmental Factors on PA Expression We selected five $S$. aquaticus genotypes, five $S$. jacobaea genotypes, and five natural hybrid genotypes for experimental use. We also included $10 \mathrm{~F}_{1}$ genotypes, including five pairs of full-sibs. Each pair of sibs was comprised of one genotype harvested from a $S$. aqauticus mother, and one genotype harvested from a $S$. jacobaea mother.
In order to produce clonal plantlets, seeds were sterilized with a $1 \%$ bleach solution and germinated in glass vials on MS medium containing $6 \mathrm{~g} / \mathrm{l}$ agar. After germination, roots were removed and the shoots were transplanted to vials with MS medium containing $6 \mathrm{~g} / \mathrm{l}$ agar and $100 \mathrm{mg} / \mathrm{l}$ benzylaminopurine (BAP). After 2-3 wk two to 6 shoots were formed. These shoots were separated and put individually into vials with MS medium with $6 \mathrm{~g} / \mathrm{l}$ agar and $100 \mathrm{mg} / \mathrm{l} \mathrm{BAP}$. This procedure was repeated until enough replicates were obtained for each genotype. Finally, individual shoots were placed in vials with MS medium with $6 \mathrm{~g} / \mathrm{l}$ agar to promote root growth. After 2 wk on this medium, roots were formed, and the plantlets were potted in soil.

One equal sized clonal plantlet from most genotypes was transplanted into each of 6 experimental columns $(1 \mathrm{~m}$ length, $15 \mathrm{~cm}$ diam), yielding a total of 136 experimental plants. We aimed for 150 plants, but due to variance in sizes and difficulties with cloning, only 136 plants were used, giving an average of 22 plants per experimental treatment. For each treatment, we aimed to include 5 genotypes of each parental species, 5 natural hybrid genotypes, and $10 \mathrm{~F}_{1}$ hybrid genotypes.

The experiment was established to test a combination of two nutrient and three water treatments. One meter tall columns were filled with sieved dune sand. In half the columns, the dune sand was mixed with 'Osmocote' slow release fertilizer $(\mathrm{N}: \mathrm{P}: \mathrm{K}=15: 11: 13+2 \mathrm{MgO})$ at a concentration of $1.3 \mathrm{~g} / 1$ sand to provide a nutrient rich medium. After establishment of seedlings, the bottoms of the columns were placed in water of three different depths: 5 , 50 , and $100 \mathrm{~cm}$. A previous study (Kirk et al. 2005b) showed that columns placed in $5 \mathrm{~cm}$ of water created drought-like conditions. Columns placed in $50 \mathrm{~cm}$ of water created conditions, which did not subject plants to waterrelated stress, and columns were placed into $100 \mathrm{~cm}$ of water mimicked flooding (soil saturation). Columns were placed in a climate chamber for the duration of the experiment (light $16 \mathrm{~h}$, temperature $20 / 15^{\circ} \mathrm{C}$, relative humidity $70 \%$ ).

All columns were given sufficient water at the beginning of the experiment to allow for seedling establishment. At the beginning of the experiment, soil throughout the total length of the column was moist. Experimental conditions were established $2 \mathrm{wk}$ after seedlings were transplanted to columns, and the experiment was subsequently continued for $10 \mathrm{wk}$. Plants were not watered from the top during this period. Roots and shoots were harvested separately, and were dried in an oven for $3 \mathrm{~d}$ at $50^{\circ} \mathrm{C}$.

PA Extraction and Identification All dried leaves and roots from each plant were separately milled to a fine powder and homogenized. Milled samples were stored in a freezer at $-0^{\circ} \mathrm{C}$ until use. For extraction, approximately $15 \mathrm{mg}$ of 
plant material were extracted according to a modified version (de Boer 1999) of the acid-base extraction method (Hartmann and Zimmer 1986). Extractions were dissolved in methanol containing heliotrine at a concentration of $1 \mu \mathrm{g} / \mathrm{ml}$ (Latoxan, France) as an internal standard and analyzed by gas chromatography (GC). Final concentrations of each PA within the sample were calculated by integrating the GC peaks and converting these areas to concentration by using the known concentration of the internal standard. Conditions (injector $250^{\circ} \mathrm{C}$, temperature program $220^{\circ} \mathrm{C}-250^{\circ} \mathrm{C} 5^{\circ} \mathrm{C} / \mathrm{min}$, split mode $1: 30$, carrier gas $\mathrm{N}_{2} 0.9 \mathrm{ml} \mathrm{min}^{-1}$, pressure $56 \mathrm{kPa}$; detector NPD) were controlled by a Hewlett Packard gas chromatographer (model 6890). GC peaks were compared with known references to identify sample composition. Identities of PAs from known reference samples were previously confirmed by using GC-MS (Macel et al. 2002). $\mathrm{PA}_{1}$ and $\mathrm{PA}_{2}$ were confirmed to be PAs, and florosenine was identified by GC-MS according to Witte et al. (1992).

Statistics We tested PA concentrations and diversity separately for roots and shoots, since PAs may interact both with root and with shoot pathogens and herbivores. We analyzed diversity in two ways. First, we counted the absolute number of PAs produced in shoots and roots of each plant group across differing treatments. This is biologically relevant because the production of each PA requires the activation of at least one new enzymatic pathway within the plant (e.g., Pelser et al. 2005). We refer to this measure of diversity as PA richness throughout the remainder of the text. Differences in both PA richness and total PA concentration were analyzed with ANOVAs, including interaction terms, for which we identified the fixed factors as water treatments, nutrient treatments, and taxa. Taxa denote parental species, $F_{1}$ hybrids, and natural hybrids. Shoot to root ratio was used as a covariate because it was assumed that root biomass is proportional to PA production, and because the size of the shoots is not related to PA production (Hol et al. 2003). Relatively large shoots may lead to a dilution of PAs. We first tested for maternal effect on PA expression in $F_{1}$ hybrids, by including only $F_{1}$ hybrids in the analysis. Previous research has shown that maternal effects can affect both growth (Kirk et al. 2005b) and reproductive fitness (Kirk et al. 2005c) of $F_{1}$ hybrids between $S$. jacobaea and S. aquaticus. Since we found that the maternal parent was never a significant factor in the analyses, we treated all $\mathrm{F}_{1}$ hybrids as one group for subsequent ANOVAs by using the entire data set.

We also analyzed PA diversity by applying principal component analysis (PCA) to quantitative PA data, which is likely most ecologically relevant from the perspective of plant defense. We applied ANOVAs to each principal component (PC) to test whether nutrient and water treatments and plant taxa had significant effects on PA composition. We then identified individual PAs that were highly correlated with each PC. All tests were performed with SPSS 8.0 (SPSS Inc. 1998).

\section{Results}

Eleven PAs were identified during our analyses (Table 1). We found eight PAs that commonly occurred in S. jacobaea (eight in the shoots, and eight in the roots). Additionally, $\mathrm{PA}_{1}$ was present in low amounts in two plants of $S$. jacobaea and florosenine (Fig. 1) in one plant. To our knowledge, neither of these PAs has been reported previously from $S$. jacobaea individuals, and may represent PAs introgressed from the Zwanenwater hybrid zone. Ten PAs were present in S. aquaticus, of which the rare PA otosenine (Fig. 1) was found only in S. aquaticus. In contrast to findings for $S$. jacobaea, $\mathrm{PA}_{1}$ almost always was present in $S$. aquaticus shoots. The reverse was true for jacobine. All eleven PAs were present among both natural hybrid and artificial hybrid genotypes. Florosenine appeared to be specific to hybrids, although trace amounts were expressed by one S. jacobaea plant.

There was no significant effect of, or interaction involving plant taxa on either shoot or root PA concentrations (Table 2 Fig. 2). In shoots, PA concentration was affected by both water, and an interaction between water and nutrient treatments. Pyrrolizidine alkaloid concentrations were approximately equal in all nutrient-rich treatments (regardless of water treatment), while in sand without nutrients, concentrations were high in the intermediate water treatment compared to other treatments. In roots, PA concentration was affected by both water and nutrient effects (Table 2). PA concentration increased with increasing soil wetness, and was higher in sand without nutrients than in sand with nutrients (Fig. 2).

PA richness in the shoots differed significantly among taxa (Table 3). Averaged over all treatments, the number of PAs per plant $( \pm \mathrm{SE})$ were, respectively, $3.96 \pm 0.35,3.59 \pm$ $0.33,4.13 \pm 0.33,4.80 \pm 0.24$ for $S$. jacobaea, $S$ aquaticus, natural hybrids, and $F_{1}$ hybrids. In shoots, PA richness also was affected by an interaction between nutrient and water treatments and interactions between nutrient treatment and taxa (Table 3). The latter interaction is caused mainly by low PA richness of $S$. aquaticus in medium and dry nutrient rich conditions. In the roots, water and taxa were both significant factors; PA richness was higher in wetter conditions, and $S$. aquaticus and $\mathrm{F}_{1}$ hybrids exhibited higher PA richness than $S$. jacobaea, with variable PA richness in natural hybrids (Fig. 3).

PCA yielded 2 components (Table 4) for PAs in plant shoots, which cumulatively explained $85.6 \%$ of the varia- 


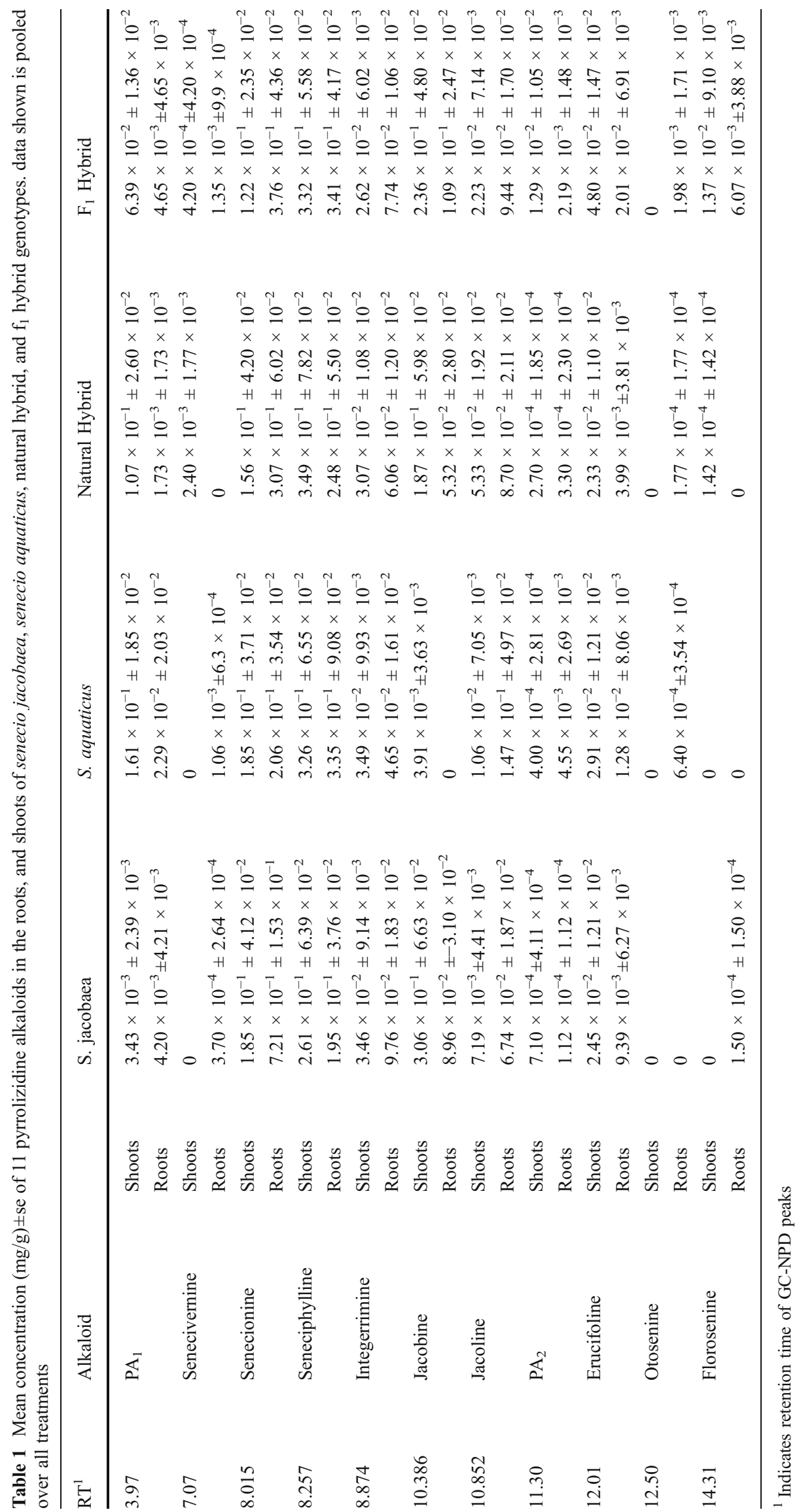


Fig. 1 Chemical structures of otosenine and florosenine

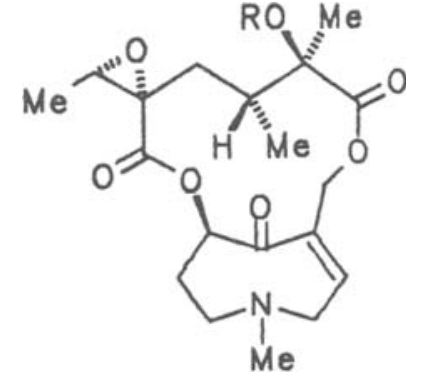

Otosenine $\mathrm{R}=\mathrm{H}$

Florosenine $\mathrm{R}=\mathrm{Ac}$

tion in PA expression. The first component (PC1) mostly explained variation in the least metabolically derived alkaloids identified in this experiment [i.e., was significantly correlated with senecionine $(r=0.68)$, seneciphylline $(r=$ $0.99)$, and integerrimine $(r=0.74)$, and to a lesser extent variation in jacobine $(r=0.21)$, jacoline $(r=0.47)$, and erucifoline $(r=0.38)$ (Table 4)]. The second component (PC2) explained variation in jacobine $(r=0.98)$, florosenine $(r=0.44), \mathrm{PA}_{1}(r=-0.29)$, senecionine $(r=-0.31)$ (Table 4). PC1 was affected significantly by all abiotic conditions and their interaction. Scores for PC1 were higher in sand without nutrients, and were low in wet and high in intermediate (moisture) conditions. PC2 was affected significantly by taxa with the parents that showed the most extreme scores $(S$. jacobaea: $0.34 \pm 0.17 \mathrm{a}, S$. aquaticus: $-0.61 \pm 0.17 \mathrm{~b})$. Mean hybrid scores were intermediate to those of parental species, but natural hybrids were statistically equal to $S$. aquaticus, while $\mathrm{F}_{1}$ hybrids were statistically equal to $S$. jacobaea (natural hybrids $-.04 \pm 0.17 \mathrm{~b}, \mathrm{~F}_{1}$ hybrids $0.16 \pm 0.12 \mathrm{a}$; different letters indicate significant differences). Another significant main effect was found for nutrients with scores for nutrient rich conditions $(0.31 \pm 0.11)$ higher than for sandy soils $(-0.38 \pm 0.11)$.

Two principal components (PCs) accounted for $88.9 \%$ of the variation in root PA expression. As in the shoots, the first component (PC1) mostly explained variation in the least metabolically derived alkaloids [i.e., senecionine $(r=0.95)$, seneciphylline $(r=0.66)$, and integerrimine $(r=0.77)$, and to a lesser extent variation in jacoline $(r=0.47)$, and erucifoline $(r=0.25)$ (Table 4)]. The second component (PC2) explained variation in senecionine $(r=-0.31)$, seneciphylline $(r=0.75)$, integerrimine $(r=$ $0.26)$, jacoline $(r=0.6), \mathrm{PA}_{2}(r=0.5)$, and erucifoline $(r=$ 0.48). All three main effects (taxa, water, nutrients) were significant for PC1. Again, parents showed the most extreme scores (S. jacobaea: $0.53 \pm 0.18 \mathrm{a}$, S. aquaticus: $-0.31 \pm$ $0.17 b)$. Natural hybrids statistically were equal to $S$. aquaticus, while $\mathrm{F}_{1}$ hybrids had intermediate mean scores, but statistically were equal to both parents (natural hybrids: $-.21 \pm 0.17 \mathrm{~b}, \mathrm{~F}_{1}$ hybrids: $0.01 \pm 0.12 \mathrm{ab}$; different letters indicate significant differences). Scores for PC1 decreased with dryer conditions and were lower in nutrient rich soils. PC2 showed significant mains effects of taxa and nutrients and a significant interaction between water and nutrients. Parental taxa showed the most extreme scores (S. jacobaea: $-0.84 \pm 0.17 \mathrm{a}$, S. aquaticus: $0.42 \pm 0.16 \mathrm{~b})$. Hybrid means
Table 2 Effect of nutrient and water treatment, and plant taxa (fixed factors) on pyrrolizidine alkaloid concentration in the roots and shoots of senecio jacobaea, senecio aquaticus, natural hybrids, and $\mathrm{f}_{1}$ hybrids. shoot to root ratio (sr ratio) of the plant was used as a covariate

\begin{tabular}{lrrrrr}
\hline Source & Type III Sum of Squares & $d f$ & Mean Square & \multicolumn{1}{l}{$F$} \\
\hline Shoots & & & & & \\
Covariate SR ratio & .640 & 1 & .640 & 1.528 & .219 \\
Taxa & .726 & 3 & .242 & .578 & .631 \\
Nutrient & 1.465 & 1 & 1.465 & 3.497 & .063 \\
Water & 6.632 & 2 & 3.316 & 7.917 & .001 \\
Taxa * nutrient & .408 & 3 & .136 & .325 & .807 \\
Taxa* water & 4.152 & 6 & .692 & 1.652 & .140 \\
Nutrient * water & 10.123 & 2 & 5.062 & 12.085 & $<.001$ \\
Taxa* nutrient * water & 2.846 & 6 & .474 & 1.132 & .348 \\
Error & 46.490 & 111 & .419 & & \\
Roots & & & & & \\
Covariate SR ratio & .794 & 1 & .794 & 1.292 & .258 \\
Taxa & 4.059 & 3 & 1.353 & 2.202 & .092 \\
Nutrient & 6.884 & 1 & 6.884 & 11.204 & .001 \\
Water & 6.549 & 2 & 3.275 & 5.329 & .006 \\
Taxa * nutrient & 1.900 & 3 & .633 & 1.031 & .382 \\
Taxa * water & 1.507 & 6 & .251 & .409 & .872 \\
Nutrient * water & .639 & 2 & .320 & .520 & .596 \\
Taxa* nutrient * water & 7.858 & 6 & 1.310 & 2.132 & .055 \\
Error & 68.203 & 111 & .614 & & \\
\hline
\end{tabular}


Fig. 2 Pyrrolizidine alkaloid (PA) concentration in the shoots and roots of Senecio jacobaea (black), Senecio aquaticus (white), natural hybrids (dark grey), and $\mathrm{F}_{1}$ hybrids (light grey) in a factorial design with two nutrient levels and three water levels. Vertical bars represent standard error
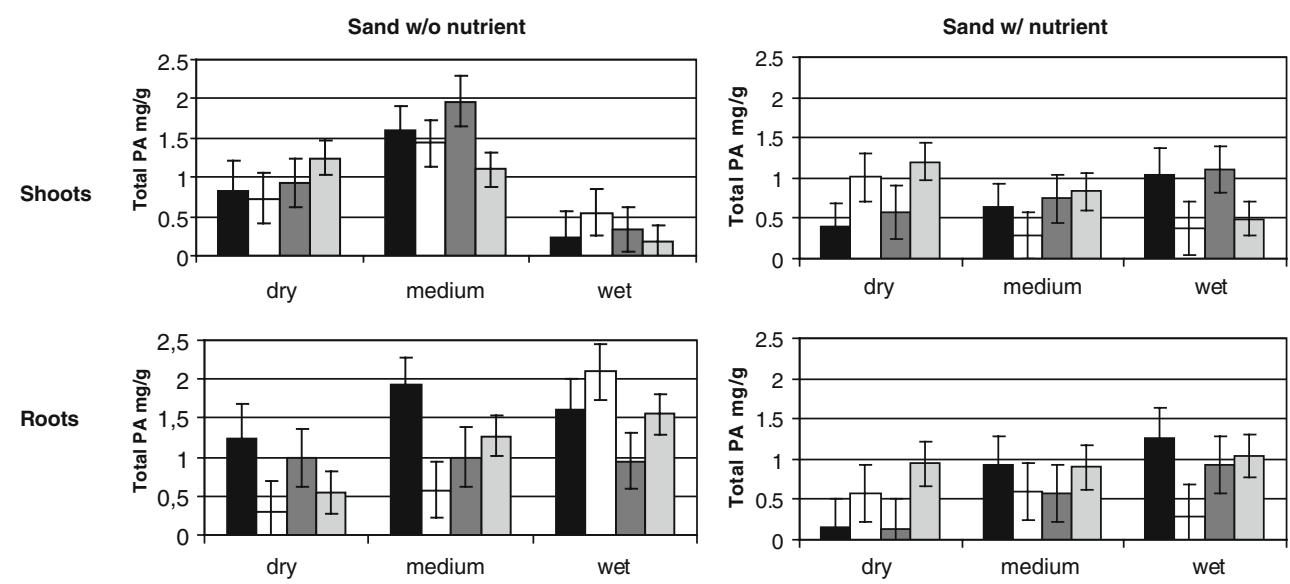

were intermediate to parental means, but both hybrids groups were statistically equal to $S$. aquaticus (natural hybrids: $-.01 \pm 0.16 \mathrm{~b}, \mathrm{~F}_{1}$ hybrids: $0.15 \pm 0.11 \mathrm{~b}$; different letters indicate significant differences).

\section{Discussion}

We found that both environmental and taxa effects mediate the expression of PAs in the roots and shoots of the plant species presented here.

Environmental Factors Total PA concentration in roots and shoots is influenced by both soil moisture and nutrient availability (Salmore and Hunter 2001; Hol et al. 2003).
According to the resource availability hypothesis, which postulates that plants should make higher investments in defense in the absence of abundant resources (Coley et al. 1985), PA concentrations are expected to be higher when nutrient availability is low. This was the case in our study; trends showed higher PA concentrations in sand without nutrients compared to sand with nutrients. This finding corroborates evidence presented by Hol et al. (2003) that PAs were diluted when $S$. jacobaea plants were grown on nutrient-rich media, due to rapid accumulation of biomass in relation to PA production.

The influence of soil moisture and nutrients on PA richness in the shoots was relatively small. In the roots, PA richness increased with increasing soil moisture. This suggests that differences in PA richness may play a large
Table 3 Effect of nutrient and water treatment, and plant taxa (fixed factors) on pyrrolizidine alkaloid richness in the roots and shoots of senecio jacobaea, senecio aquaticus, natural hybrids, and $\mathrm{f}_{1}$ hybrids. shoot to root ratio (sr ratio) of the plant was used as a covariate

\begin{tabular}{lrrrrr}
\hline Source & Type III Sum of Squares & $d f$ & Mean Square & $F$ & $P$ \\
\hline Shoot & & & & & \\
Covariate SR ratio & 1.758 & 1 & 1.758 & .577 & .449 \\
Taxa & 30.530 & 3 & 10.177 & 3.339 & .022 \\
Nutrient & .439 & 1 & .439 & .144 & .705 \\
Water & 5.421 & 2 & 2.711 & .889 & .414 \\
Taxa * nutrient & 31.988 & 3 & 10.663 & 3.499 & .018 \\
Taxa * water & 24.382 & 6 & 4.064 & 1.333 & .248 \\
Nutrient * water & 67.319 & 2 & 33.660 & 11.044 & $<.001$ \\
Taxa * nutrient * water & 8.652 & 6 & 1.442 & .473 & .827 \\
Error & 338.292 & 111 & 3.048 & & \\
Root & & & & & \\
Covariate SR ratio & 2.364 & 1 & 2.364 & .806 & .371 \\
Taxa & 28.433 & 3 & 9.478 & 3.233 & .025 \\
Nutrient & 1.727 & 1 & 1.727 & .589 & .444 \\
Water & 42.868 & 2 & 21.434 & 7.312 & .001 \\
Taxa * nutrient & 22.180 & 3 & 7.393 & 2.522 & .061 \\
Taxa * water & 21.237 & 6 & 3.539 & 1.207 & .308 \\
Nutrient * water & 1.975 & 2 & .988 & .337 & .715 \\
Taxa * nutrient * water & 7.419 & 6 & 1.236 & .422 & .863 \\
Error & 325.386 & 111 & 2.931 & & \\
\hline
\end{tabular}


Fig. 3 Pyrrolizidine Alkaloid (PA) richness, defined as the number of PAs detected within each sample, in the shoots and roots of Senecio jacobaea (black), Senecio aquaticus (white), natural hybrids (dark grey), and $\mathrm{F}_{1}$ hybrids (light grey) in a factorial design with two nutrient levels and three water levels. Vertical bars represent standard error
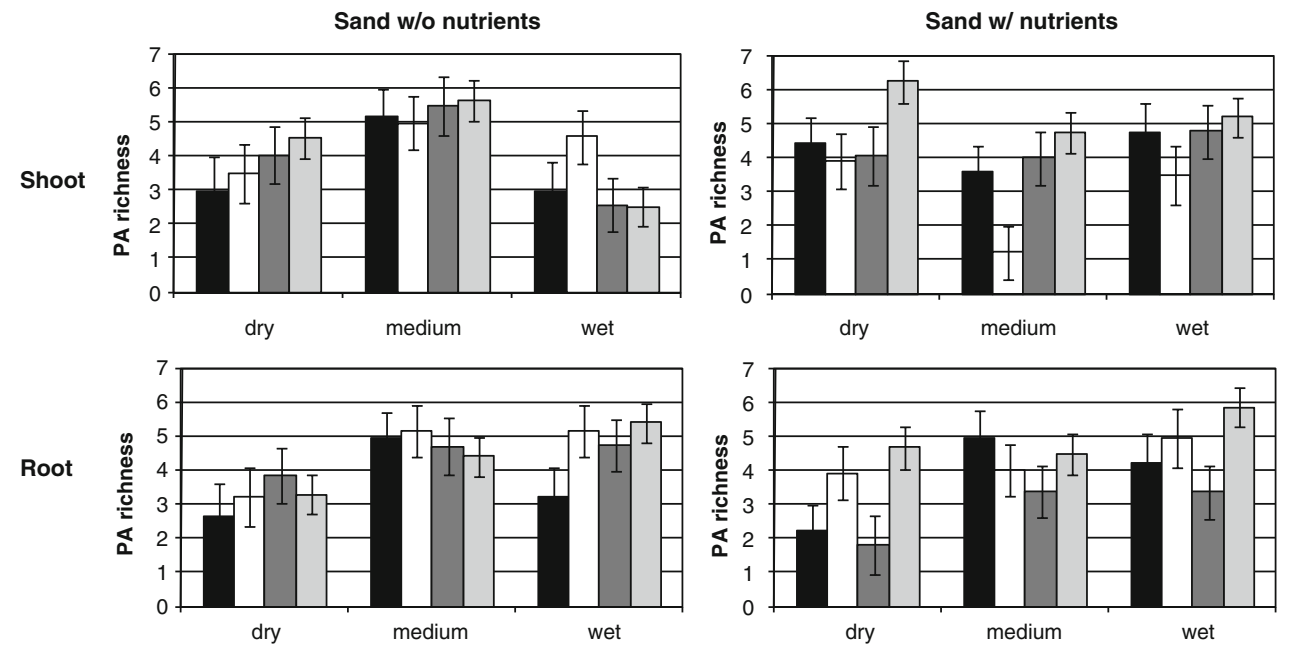

role in below-ground plant defense because pathogenic pressure will rise with increasing soil moisture (e.g., Shafer and Kotonan 2003). Based on limited data, below-ground defense seems to be more important for some species than others; Brassicaceous plants produce greater concentrations and a higher diversity of glucosinolates in roots than in shoots, and at least one glucosinolate has higher toxicity below-ground than above-ground (van Dam et al. 2009). In contrast, Milkweed allocates more resources to aboveground plant defense compared to below-ground defense (Rassman et al. 2009).

Nutrients and water conditions had a strong effect on PA expression in shoots and roots for both PCAs. In the shoots seneciphylline (PC1) and jacobine (PC2), and in the roots senecionine (PC1) and seneciphylline (PC2), were correlated strongly with PCA scores suggesting that the concentrations of these PAs are most influenced by environmental conditions. Concentration of jacobine in the shoots more than doubled when nutrient concentrations increased, although total PA concentration decreased. This might have implications for plant defense because jacobine has been shown to be more effective against thrips than all other PAs found in $S$. jacobaea (Leiss et al. 2009).

Taxa Plant taxa (including hybrid groups) never showed differences in total PA concentration in plant shoots or
Table 4 Effects of nutrient treatment, water treatment, and plant taxa on principal components (pcs) that are correlated with pyrrolizidine alkaloids (pas) expression in roots and shoots of senecio

\footnotetext{
${ }^{1}$ Indicates percent of total PA variation explained by each $\mathrm{PC}$

${ }^{2}$ Indicates PAs that are significantly correlated with each PC $(P<0.05)$

${ }^{3}$ Significant factors represent single factors and/or interactions that had significant effects on PC values in ANOVA analyses
}

\begin{tabular}{|c|c|c|c|c|}
\hline & Principal Component & $\%$ variation $^{1}$ & Correlated $\mathrm{PAs}^{2}$ & Significant Factors $^{3}(P<.050)$ \\
\hline \multirow[t]{8}{*}{ Shoots } & \multirow[t]{5}{*}{1} & \multirow[t]{5}{*}{53.0} & $(+)$ Senecionine & Nutrient \\
\hline & & & $(+)$ Seneciphylline & Water \\
\hline & & & $(+)$ Integerrimine & Water*Nutrient \\
\hline & & & $\begin{array}{l}(+) \text { Jacobine } \\
(+) \text { Jacoline }\end{array}$ & \\
\hline & & & $(+)$ Erucifoline & \\
\hline & \multirow[t]{3}{*}{2} & \multirow[t]{3}{*}{32.6} & $(-) \mathrm{PA} 1$ & Taxa \\
\hline & & & $(-)$ Senecionine & Nutrient \\
\hline & & & $\begin{array}{l}(+) \text { Jacobine } \\
(+) \text { Florosenine }\end{array}$ & \\
\hline \multirow[t]{9}{*}{ Roots } & \multirow[t]{4}{*}{1} & \multirow[t]{4}{*}{64.7} & $(+)$ Senecionine & Taxa \\
\hline & & & $(+)$ Seneciphylline & Water \\
\hline & & & $(+)$ Integerrimine & Nutrient \\
\hline & & & $\begin{array}{l}(+) \text { Jacoline } \\
(+) \text { Erucifoline }\end{array}$ & \\
\hline & \multirow[t]{5}{*}{2} & \multirow[t]{5}{*}{24.2} & $(-)$ Senecionine & Taxa \\
\hline & & & $(+)$ Seneciphylline & Nutrient \\
\hline & & & $(+)$ Integerrimine & Water*Nutrient \\
\hline & & & $\begin{array}{l}(+) \text { Jacoline } \\
(+) \text { PA2 }\end{array}$ & \\
\hline & & & $(+)$ Erucifoline & \\
\hline
\end{tabular}


roots. This suggests that selective pressure by different natural enemies does not play a large role in determining total PA concentration, because $S$. aquaticus and $S$. jacobaea grow in different environments (nutrient rich and moist vs. nutrient poor and dry), with a different host of herbivores and soil bacteria and fungal communities (Kirk et al. 2005b; Singh et al. 2009). In contrast to total PA concentration, PA richness (diversity) was significantly different between taxa for shoots and roots. PA richness tended to be higher in shoots and roots of the $\mathrm{F}_{1} \mathrm{~s}$ compared to the parental species, and the natural hybrids and the $\mathrm{F}_{1} \mathrm{~s}$ contained PAs from both S. aquaticus and S. jacobaea. PA expression was affected significantly by taxa in both shoots and roots. Based on principal component analysis, we found that taxa was a significant factor with regard to PC2 in the shoots, which is explained mostly by variation in jacobine content. For PC1, which was highly correlated with seneciphylline in the shoots, there was no effect of taxa. In plant roots, taxa was a significant factor for both principal components. The effects of selective pressures by natural enemies on secondary metabolite composition have been difficult to demonstrate experimentally (i.e., Macel et al. 2005; Albrechtsen et al 2007), and the comparative method used here is a promising avenue of further research.

Novel Compounds With regard to hybridization between $S$. jacobaea and $S$. aquaticus, both $\mathrm{F}_{1}$ and natural hybrids produce the PA florosenine, which may be a novel product of hybridization in the Zwanenwater population. Florosenine has been reported previously from the South American Senecio species S. glaber (Reina et al. 1993) and $S$. leptolobus (Mendez et al. 1990), as well as from a Swiss population of $S$. aquaticus (Pelser et al. 2005). Florosenine was never found in S. aquaticus from the Zwanenwater nature reserve during this current study, or during previous ones (Kirk et al. 2004). Trace amounts of florosenine were found in one S. jacobaea individual here, but this occurrence may represent introgression, since this PA has never been reported from other S. jacobaea populations, and was not found in either Zwanenwater S. jacobaea genotypes, or control populations from a variety of European locations analyzed in a previous study (Kirk et al. 2004). Florosenine is the O-acetyl derivative of otosenine. Mechanistically, it is possible that hybridization combines the ability of $S$. jacobaea to acetylate PAs, and the ability of $S$. aquaticus to synthesize otosenine. If such inter-specific epistatic interactions between enzymes and substrates can result in the production of unique PA structures, then hybridization within the genus Senecio may be a mechanism for structural PA diversification.

This study system is useful for studying variation in PA expression. Environmental conditions play an important regulatory role in PA concentrations in above-and below- ground plant parts, and these interactions seem mainly to be governed by senecionine, seneciphylline, and jacobine. A general problem with these types of experiments is that it is not yet possible to distinguish between the direct effects of the treatments and the indirect effect of the treatments caused by changes in the microbial community in the soil. Although the induced changes in PA expression in richness are likely to be relevant for plant defense, this still remains to be tested experimentally. The evaluation of natural selection on different hybrid genotypes that possess different combinations of PAs may be extremely useful for elucidating the role of PA diversity or expression of other secondary metabolites in plants (e.g., Lexer et al. 2003).

Acknowledgements Heather Kirk thanks the Natural Sciences and Engineering Research Council of Canada (NSERC) for financially supporting her research. Also thanks to Jung van der Meulen, Margriet Peet, and Helene de Vos for technical assistance, and Thomas Hartmann for assistance in identifying PA structures. We thank three anonymous reviewers for useful comments on the manuscript.

Open Access This article is distributed under the terms of the Creative Commons Attribution Noncommercial License which permits any noncommercial use, distribution, and reproduction in any medium, provided the original author(s) and source are credited.

\section{References}

Adler, L. S., and Kittelson, P. M. 2004. Variation in Lupinus arboreus alkaloid profiles and relationships with multiple herbivores. Biochem. Syst. Ecol. 32:371-390.

Albrechtsen, B. R., Gutierrez, L., Fritz, R. S., Fritz, R.D., and ORIANS, C. M. 2007. Does the differential seedling mortality caused by slugs alter the foliar traits and subsequent susceptibility of hybrid willows to a generalist herbivore? Ecol. Entom. 32:211220.

CHEEKE, P. R. 1988. Toxicity and metabolism of pyrrolizidine alkaloids. J. Anim. Sci. 66:2343-2350.

Close, D. C., Mcarthur, C., Hagerman, A. E., and Fitzgerald, H. 2005. Differential distribution of leaf chemistry in eucalypt seedlings due to variation in whole-plant nutrient availability. Phytochemistry. 66:215-221.

Coley, P. D., Bryant, J. P., and Chapin, F. S. III. 1985. Resource availability and plant antiherbivore defense. Science 230:895899.

De Boer, N. J. 1999. Pyrrolizidine alkaloid distribution in Senecio jacobaea minimizes losses to generalist feeding. Entomol. Exp. Appl. 91:169-173

FRITZ, R. S. 1999. Resistance of hybrid plants to herbivores: genes, environment, or both? Ecology 80: 382-391.

Hartmann, T., and Dierich, B. 1998. Chemical diversity and variation of pyrrolizidine alkaloids of the senecionine type: biological need or coincidence? Planta 206: 443-451.

Hartmann, T., and TopPel, G. 1987. Senecionine $N$-oxide, the primary product of pyrrolizidine alkaloid biosynthesis in root cultures of Senecio vulgaris. Phytochemistry 26:1639-1643.

HaRtManN, T., and WitTE, L. 1995. Chemistry, biology and chemoecology of the pyrrolizidine alkaloids. pp 156-233 in Pelletier 
SW (ed) Alkaloids: Chemical and Biological Perspectives. Vol. 9, Pergamon Press Elmsford, New York,

HARTMANN, T., and ZIMMER, M. 1986. Organ specific distribution and accumulation of pyrrolizidine alkaloids during the life history of two annual Senecio species. Plant Physiol. 112:67-80.

Hercus, M. J., and Hoffmann, A. A. 1999. Does interspecific hybridization influence evolutionary rates? An experimental study of laboratory adaptation in hybrids between Drosophila serrata and Drosophila birchii. Proc. Roy. Soc. London B. 266:2195-2200.

Hol, W. H. G., and VAN VeEN, J. A. 2002. Pyrrolizidine alkaloids from Senecio jacobaea affect fungal growth. J. Chem. Ecol. 28:1763-1772

Hol, W. H. G., Macel, M., Van Veen, J. A., and VAN DER MEIJDEN, E. 2004. Root damage and aboveground herbivory change concentration and composition of pyrrolizidine alkaloids of Senecio jacobaea. Bas.Appl. Ecol. 5:253-260

Hol, W. H. G., VRieling K., and VAN Veen J. A. 2003. Nutrients decrease pyrrolizidine alkaloid concentrations in Senecio jacobaea. New Phytol. 158:175-181

Holton, M. K., LindROTH, R. L., and Nordheim, E. V. 2003. Foliar quality influences tree-herbivore-parasitoid interactions: effects of elevated CO2, O-3, and plant genotype. Oecologia 137:233-244.

Kirk, H., Macel, M., Klinkhamer, P. G. L., and Vrieling, K. 2004. Natural hybridization between Senecio jacobaea and Senecio aquaticus: Molecular and chemical evidence. Mol. Ecol. 13:2267-2274

KIRK, H., ChOI, Y. H., KIM, H. K., Verpoorte, R., and VAN DER MeIJDEN, E. 2005a. Comparing metabolomes: the chemical consequences of hybridization in plants. New Phytol.167:613-622

KirK, H., VRIELING, K., and KlinKhamer P. G. L. 2005b. Maternal effects and heterosis influence the fitness of plant hybrids. New Phytol. 166:685-694.

Kirk, H., Vrieling, K., and Klinkhamer P. G. L. $2005 \mathrm{c}$. Reproductive fitness of hybrids between Senecio jacobaea and Senecio aquaticus (Asteraceae). Am. J. Bot. 92:1467-1473.

KowalchuK, G. A., Hol W. H. G., and Van Veen J. A. 2006. Rhizosphere fungal communities are influenced by Senecio jacobaea pyrrolizidine alkaloid content and composition. Soil Biol. Biochem. 38:2852-2859

LeISS, K. A., ChOI, Y. H., ABDEL-FARID, I. B., Verpoorte, R., and KlinkhameR, P. G. L. 2009. NMR Metabolomics of Thrips (Frankliniella occidentalis) Resistance in Senecio Hybrids. J. Chem. Ecol. 35:219-229

LEXER, C., RANDELL, R. A., and RIESEBERG, L. H. 2003. Experimental hybridization as a tool for studying selection in the wild. Ecology 84: 1688-1699.

Loney, P. E., Mcarthur. C., SAnson, G. D., Davies, N. W., Close, D. C., and JoRDAN, G. J. 2006. How do soil nutrients affect within-plant patterns of herbivory in seedlings of Eucalyptus nitens? Oecologia 150:409-420.

MACEL, M. 2003. On the evolution of the diversity of pyrrolizidine alkaloids: the role of insects as selective forces. Phd. dissertation, Leiden University

Macel, M., Klinkhamer, P. G. L., Vrieling, K., and Van Der MEIJDEN, E. 2002. Diversity of pyrrolizidine alkaloids in Senecio species does not affect the specialist herbivore Tyria jacobaea. Oecologia 133:541-555

MACEL, M., VRiELING, K., and KLINKHAMER, P. G. L. 2004. Variation in pyrrolizidine alkaloid patterns of Senecio jacobaea. Phytochemistry 65:865-873.

Macel, M., Bruinsma, M., Dijkstra, S.M., OoijendiJK, T., NiEMEYer, H. M., and KlinKHAMER, P. G. L. 2005. Differences in effects of pyrrolizidine alkaloids on five generalist insect herbivore species. J. Chem. Ecol. 31:1493-1508.
Macel, M., and Klinkhamer, P. G. L. 2009. Chemotype of Senecio jacobaea affects damage by pathogens and insect herbivores in the field. Evol. Ecol. doi:10.1007/s10682-009-9303-7.

Mendez, M. D., Rietcorrea, F., Schild, A. L., and Martz, W. 1990. Experimental poisoning of cattle and chicks by 5 Senecio species. Pesq. Vet. Brasil. 10:63-69.

ORIANS, C. M. 2000. The effects of hybridization in plants on secondary chemistry: implications for the ecology and evolution of plant-herbivore interactions. Am. J. Bot. 87: $1749-1756$.

Pelser, P. B. De Vos, H., Theuring, C., Beuerle, T., Vrieling, K., and HARTMANN, T. 2005. Frequent gain and loss of pyrrolizidine alkaloids in the evolution of Senecio section Jacobaea (Asteraceae). Phytochemistry 66:1285-1295

Rasmann, S., Agrawal, A. A., Cook, S. C., and Erwin, A. C. 2009. Cardenolides, induced responses, and interactions between above-and belowground herbivores of milkweed (Asclepias spp.). Ecology 90:2393-2404.

RAUSCHER, M. D. 2001. Co-evolution and plant resistance to natural enemies. Nature 411:857-864.

Reina, M., Delafuente, G., Villarroel, L., and Torres, R. 1993. Pyrrolizidine alkaloids from Senecio erraticus, S. glaber, and $S$. microphyllus. Anal. Quimica 89:387-390.

Rieseberg, L. H., Archer, M.A., and WAyne, R. K. 1999. Transgressive segregation, adaptation and speciation. Heredity 83:363-372.

SAlMORE, A.K., and HUNTER, M.D. 2001. Environmental and genotypic influences on isoquinoline alkaloid content in Sanguinaria Canadensis. J. Chem. Ecol. 27: 1729-1747.

SCHAFER, M., and KotANEN, P. M. 2003. The influence of soil moisture on losses of buried seeds to fungi. Int. J. Ecol. 24:255263.

Schaffner, U., Vrieling, K., and Van Der Meijden, E. 2003. Pyrrolizidine alkaloid content in Senecio: ontogeny and developmental constraints. Chemoecology 13:39-46

Singh, B. K., Dawson, L. A., Macdonald, C. A., and Buckland, L. M. 2009. Impact of biotic and abiotic interaction on soil microbial communities and functions: A field study. Appl. Soil Ecol. 41:239-248.

SPSS Inc. 1998. SPSS Base 8.0 User's Guide SPSS Inc. Chicago.

STACE, C. A. 1975. Hybridization and the Flora of the British Isles. London, England: Academic Press for the Botanical Society of the British Isles.

Trigo, J.R., LEAL, I.R., MATZENBACHER, N.I., and LEWINSOHN, T.M. 2003. Chemotaxonomic value of pyrrolizidine alkaloids in southern Brazil Senecio (Senecioneae: Asteraceae). Biochem. Syst. Ecol. 31:1011-1022.

VAn Dam, N. M., Tytgat, T., and KirkegaArD, J. 2009. Root and shoot glucosinolates: a comparison of their diversity, function and interactions in natural and managed ecosystems. Phytochem. Rev. 8:171-86

Van Dam, N., Vuister, L.W.M., BergshoefF, C., De Vos, H., and VAN DER MEIJDEn, E. 1995. The raison d'être of pyrrolizidine alkaloids in Cynoglossum officinale: deterrent effects against generalist herbivores. J. Chem. Ecol. 31:507-523

WeEda, E. J., and VAn Deursen, C. G. M. 1994. pp. 102-109 in Oecologische Flora: Wilde Planten en Hun Relaties. Volume 3. Amsterdam IVN.

WissemanN, V. 2007. Plant evolution by means of hybridization. Syst. Biodiv. 5:243-253.

Witte, L., Ernst, L., Adam, H., and Hartmann, T. 1992. Chemotypes of two pyrrolizidine alkaloid-containing Senecio species. Phytochemistry 31:559-565. 